Araştırma Makalesi

\title{
Girişimci Üniversite Anlayışı Çerçevesinde Kariyer Geliştirme Merkezi Modeli
}

\author{
Metin Işık (Prof. Dr.) \\ Sakarya Üniversitesi İletişim Fakültesi \\ metin@sakarya.edu.tr \\ Ayhan Erdem (Doç. Dr.) \\ Hasan Kalyoncu Üniversitesi İletişim Fakültesi \\ ayhan.erdem@hku.edu.tr
}

Başvuru Tarihi: 27.06.2018

Yayına Kabul Tarihi: 26.07.2018

Yayınlanma Tarihi: 30.07.2018

\section{Öz}

$\mathrm{Bu}$ çalıșmada üniversitelerde kalite anlayıșının geliștirilmesinde önemli rol oynayan stratejik örgüt yapısı ve bu örgüt yapısı bağlamında şekillenen eylem planlarına yönelik olarak geliştirilen girișimcilik temelli ve kariyer odaklı bir model önerilmiştir. Laboratuvar ve Atolyeler, Transfer ve İletişim Merkezi, Sosyal, Beşeri ve Psikoloji Sermaye Gelişim Birimi, Üniversite Temsilciği, Sektör Temsilciği ve Yönetim alt birimlerinden meydana gelen "Kariyer Geliștirme Merkezi Modeli" üniversite öğrencilerinin eğitim hayatı ve mezuniyet sonrasında uyum sağlama yeteneklerinin geliştirilmesi, yenilikçi fikirler üretmesi ve sosyal bir ortam içerisinde bu fikirleri sunup, uygulamaya geçirme firsatını gençlere sunmaktadır. Modelin geliştirilme aşamasında üniversitelerde girişimcilik eğitimine yönelik literatür incelenmiş ve ardından alt birimler oluşturularak modele son hali verilmiştir.

Anahtar Kelimeler: Girişimcilik, Üniversite, Kariyer, Model. 


\title{
Career Development Center Model in the Framework of Entrepreneurial Universities
}

\author{
Metin Işık (Prof. Dr.) \\ Sakarya University Faculty of Communication \\ metin@sakarya.edu.tr \\ Ayhan Erdem (Assoc. Prof. Dr.) \\ Hasan Kalyoncu University Faculty of Communication \\ ayhan.erdem@hku.edu.tr
}

Date Received: 27.06.2018

Date Accepted: 26.07.2018

Date Published: 30.07.2018

\begin{abstract}
In this study, Career Development Center Model is proposed for the strategic organization structure of entrepreneurial universites and the action plans of these universities. Organization structure and the action plans play an important role for encouraging the students for the entrepreneurship trends. The aim of the model is to improve the adaptability of the university students while and after the education, help to develop innovative ideas and to improve the quality of life of the university students.Within the sub-units as listed; laboratories and workshops, transfer and communication center, social, human and psychological capital development unit, university representative, sector representative and management the opportunity to present and implement innovative and self-developing ideas served the students in a social environment. During the development phase of the model, the literature on entrepreneurship education in universities was examined, and then the sub-units created and the model finalized.
\end{abstract}

Keywords: Entrepreneurship, University, Career, Model. 


\section{Giriş}

Küçük işletme sahiplerinin; girişimcilik faaliyetlerini, inovasyonları ve yaratıcılığı arttırmayönünde taşıdığıbüyük potansiyelin keşfiözellikleekonomi odaklı politikalar geliștiren yapıların dikkatlerini cezbetmektedir (Van Stel ve diğerleri, 2005; Gilbert ve diğerleri, 2004; Işık ve Ünlü, 2014, 165). Bu yöndeki teşviklerin beraberinde mezuniyet sonrasına yönelik olarak öğrencilere aktarılan "hayal kırıklıkları" içeren deneyimler, öğrencileri kendi işletmelerini açmaya yönlendirmektedir.

$\mathrm{Bu}$ tür girişimlerden övgüye değer öğrenci girişimcilerine örnek olarak; Texas üniversitesinde yurt odasında Dell firmasının temellerini atan Michael Dell, Harvard üniversitesinde oda arkadaşlarıyla birlikte Facebook'u kuran Mark Zuckerber ve Stanford Üniversitesi'nde öğrenci iken Google'ın ortak kurucusu olan Larry Page verilebilir (Gupta ve Gupta, 2017, 33). Günümüzde başarılı birer "iș adamı” olarak kabul gören bu isimler özünde yenilikçi fikirlerini ellerinde olan imkânlar dâhilinde hayata geçirmiş girișimci öğrencilerdir. Aynı zamanda bu üç ismin bilişim sektöründe yükselmiş olması ise basit bir tesadüften kaynaklanmamakta, yeni gelişen bir iş ve teknoloji kolunun akıllıca değerlendirilmesinden ibarettir. Ancak tahmin edilebileceği üzere öğrenci girişimleri yalnızca bilişim alanıyla sınırlı kalmamakta farklı sektörlerin üretim ve/veya hizmet alanlarında kendisini gösterebilmektedir. $\mathrm{Bu}$ örneklerin sunulmasındaki gaye ise yenilikçi yaklaşımların büyük finansman destekleri olmaksızın başarıya ulaşabileceğinin gösterilmesidir.

$\mathrm{Bu}$ çalışmanın üniversite öğrencilerine yönelik değer yaratma, yeni fikirleri destekleme ve bu yolda öğrencilere destek olabilecek sosyal bir çevre oluşturma misyonu taşıyacak ve bir yandan kariyer gelişimi diğer yandan da girişimcilik düzeyini geliştirecek bir modelin önerilmesidir. Bu doğrultuda ilgili literatür incelenerek modelin alt birimlerini olușturacak bileșenler ve farklı yaklaşımlar ifade edilmiştir. Çalışmanın çıktısı olarak geliştirilen model; öğrenci-üniversite birliğinin sağlanması, öğrencilerin girişimcilik düzeyinin arttırılması ve mezuniyet sonrasına yönelik kaygıların azaltılmasına yönelik uygulamalar bütünü barındırması sebebiyle önem arz etmektedir.

\section{Öğrenci Girişimciliği ve Üniversitelerde Girişimcilik Eğitimi}

Öğrenci girişimleri eğitim-öğrenim hayatı boyunca edinilen kuramsal ve uygulamalı bilgiler bütünün olumlu ve fayda sağlayacak bir biçimde kullanılmasına yönelik faaliyetleri yapısında barındırmaktadır (Ridder ve Sijde, 2006). Öğrencilik döneminde iş hayatına yönelik faaliyetlerde bulunmak ve özellikle de bir girişim faaliyetine dâhil olmak öğrencinin akademik gelişimine ket vurabilecek ve gelecekte okul başarısını etkileyebilecek bir faktör olarak değerlendirilse de (Ndirangu ve Bosire, 2004) akademik kariyer dışında kendisine farklı bir yol çizen öğrenciler için mezuniyet sonrası iş hayatına katılım yönündeki atılımlar "geç kalınmış" çabalar olarak nitelendirilmekte ve bu öğrenciler "deneyimsiz" olarak damgalanmaktadır.

Ancak üniversiteleröğrencilerin "girişimcilik kimliği" geliştirmede aktif rol oynaması, onlara yol gösterecek sektör temsilcileri ve bir bütün kampüs içinde yürütülen sosyal öğrenme süreçleri (Donnellon ve diğerleri, 2014, Rigg ve O’Dwyer, 2012; Howorth ve diğerleri, 2012) girișimcilik fikrini zihnine yerleştirmiş veya konuya ilgili olan öğrencilerin hem akademik gelişimlerinin sürdürülmesi hem de yenilikçi fikirlerin kaybolup gitmesini önleyici faktörler olarak değerlendirilebilmektedir. 
1990’lı yıllardan itibaren A.B.D’de medya ve politik söylemde kendisine sıklıkla yer bulan öğrenci girişimciliğine ilişkin olarak ülkede günümüze değin birçok kitap, makale ve farklı türlerde yayın yapılmış ve konunun toplum ve ekonomi için önemini özümseyen üniversiteler öğrenci girişimlerinin teşviki ve öğrencilere girişimcilik ruhunun aşılanması hususunda kayda değer çalışmalar yapmıştır (Vesper ve Gartner, 2001). Ancak bu çabalara rağmen Robinson ve diğerleri (2016) de belirttiği üzere üniversitelerin geleneksel eğitim yapısı girişimcilik için gerekli görülen ne psikolojik ne de uygulamalı eğitimi vermekte yetersiz kalmakta verilen eğitimler çoğu üniversite yalnızca yüzeysel kurslar ve seminerler ile sınırlı kalmaktadır. Ülkemizdeki durum göz önüne alındığında ise üniversitelerde girişimciliğe yönelik eğitimler çoğunlukla fen bilimlerinin belirli bölümleriyle sınırlı kalmakta ve ancak üniversite eğitimini yarıda bırakmış iş hayatında gerçek kimliğini bulmuş genç girișimcilerden bahsedilebilmektedir.

Öyle ki, başarılı birçok örnek verilebilirse de hali hazırda mezun olan çoğu öğrenci girişimde bulunup kendi işletmesini kurmaktansa öz yeterliliklerini kazanana kadar sektörlerinde farklı iş kollarında çalışmayı tercih etmektedir. Bu seçimin altında yatan nedenler yeni mezunların kendilerini girişimcilik yeteneklerinden mahrum hissetmeleri, konu hakkındaki bilgilerinin kısıtlı olması ve ağlarının çok sınırlı olmasından kaynaklanmaktadır (Brockhaus ve Horwitz 1986; Brown 1990; Collins ve diğerleri, 2004; Galloway ve Brown 2002; Ronstadt 1985). Bu süreçte sektöre atılan gençlerin çoğu başarısızlık korkusuyla girişim fikirlerinden vazgeçme ve yeni girişimler daha hayata geçmeden yok olma tehlikesiyle karşı karşıya kalmaktadır.

$\mathrm{Bu}$ durumun sebebi verilen geleneksel girişimcilik eğitiminde tamamen eylem odaklı bir yaklaşımın benimsendiği "sokağa çık ve yap" anlayışının hüküm sürmesidir (Ronstadt, 1985). Ancak daha çağdaş ve etkili olarak nitelendirilebilecek bir yaklaşımla ise öncelikli olarak konuya uzak olan öğrencilerin girişimcilik kariyeri hakkında farkındalığı arttırmak ve girişimciliği yeni bir opsiyon olarak sunmaktır (Donckels, 1991; Kantor, 1988). Konu hakkında yeterli farkındalığa sahip öğrenciler kapsamında düşünüldüğünde ise girişimcilik ve işletme yönetimine ilişkin yetkinliği arttıracak eğitimlerin verilmesi doğrudan faaliyete geçilmeden önce gerekli alt yapının sağlanmasına yardımcı olabilecek bir etken olarak değerlendirilmektedir. Bütünsel olarak değerlendirildiğinde bu tür bir yaklaşımın benimsenmesi girişimcilik için gerekli becerilerin ve ağ bağlantılarının edinilmesi yoluyla, öğrencilerin bir iş kurma süreci ile ilgili kendine olan güveni arttıracak ve böylece edinilen vizyon ile geleceğe yönelik eylem arasında bağlantılar oluşturulacaktır (Johannisson, 1991; Kantor, 1988).

\section{Girişimciliğe Yönelik Kariyer Geliştirme Merkezi Modeli}

Üniversitelerin kuramsal ve uygulamalı bilgiler sunmanın beraberinde; değer yaratma, yeni fikirleri destekleme ve bu yolda öğrencilere destek olabilecek sosyal bir çevre oluşturma yükümlülükleri bulunmaktadır. Bu bağlamda öğrencilerin hem sosyal yaşamlarına hem de iş yaşamlarında girişimci bireyler olarak topluma destek sağlamaları ve sosyal etki yaratmaları amaciyla üniversiteler dâhilinde "Kariyer Geliștirme Merkezi" kurulması önerilmektedir.

Geliştirilen "Kariyer Geliştirme Merkezi'nin” amacı üniversite öğrencilerinin mezuniyet sonrası iş yaşamına daha kolay bir biçimde uyum sağlamasına yardımcı 
olurken, onların yenilikçi fikirler geliştirmesi ve sosyal bir ortam içerisinde bu fikirleri sunup, uygulamaya geçirmelerini sağlamaktır.

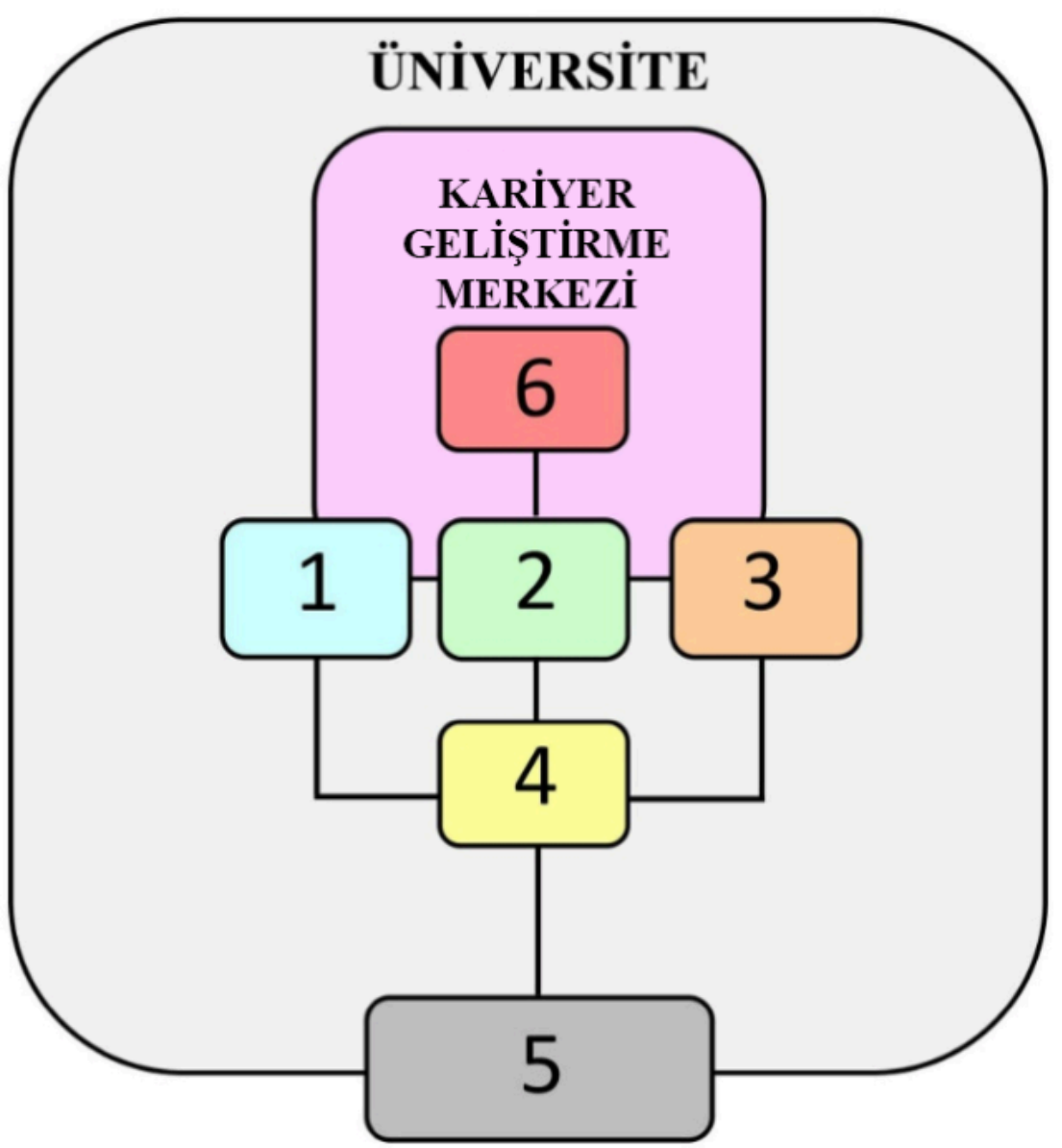

\begin{tabular}{l}
1 \\
2 \\
3 \\
\hline
\end{tabular}

Laboratuvar ve Atölveler
Transfer ve İletişim Merkezi
Sosyal, Beşeri ve Psikoloji
Sermaye Gelişim Birimi

4

5

6
Üniversite Temsilciği

Sektör Temsilciği

Yönetim

Şekil 1: Kariyer Geliştirme Merkezi Modeli

"Kariyer Geliștirme Merkezi" üniversiteler dahilinde kurulacak kapsayıcı bir merkezi bir birim dahilinde bir araya gelen ve sistematik bir bütünlük içerisinde çalışan altı farklı birimin ortak faaliyetlerini kapsamaktadır. Her biri farklı fonksiyonlara sahip bu altı birim; Laboratuvar ve Atolyeler, Transfer ve İletişim Merkezi, Sosyal, Beşeri ve Psikoloji Sermaye Gelişim Birimi, Üniversite Temsilciği, Sektör Temsilciği ve Yönetim olarak sıralanmaktadır.

\section{Laboratuvar ve Atolyeler}

Model dahilinde yer verilen ilk birim olan Labaratuvar ve Atölyeler iki farkla işleve sahiptir. Bunlar öğrencilerin fikirlerinin sınandığı ve geliştirildiği destek merkezleri ve girişimcilik üzerine eğitimin verildiği çok amaçlı kurs merkezleri olmaktır.

Buna göre laboratuvarlarda üniversitelerin farklı birimlerinden bir araya gelen akademisyenler ve deneyimli sektör temsilcileri öğrencilerin geliștirdikleri girişim ve/veya proje fikirlerini belirli yöntemler dahilinde sınayarak ve geliştirerek 
üniversite dıșı sosyal yaşama ve sektör şartlarına uygun hale getirmektedir. $\mathrm{Bu}$ doğrultuda labrotuvarlar fikirlerin güçlendiriliğ başarılı birer girişim haline gelmeleri yolunda büyük bir önem arz eden merkezler olarak görev yapmaktadır.

Atölyeler ise gerek birebir gerekse de toplu gruplar halinde öğrencilerin girişimcilik konusunda farkındalık sahibi olması ve halihazırda bu farkındalığa sahip öğrencilere girişimcilik konusunda gerekli bilgi, tecrübe ve ağların aktarıldığı düşünce grupları ve eğitim merkezleri olarak görev yapmaktadır.

Bir bütün olarak labratuvar ve atölyeler sayesinde elde edinilen kazanımlar öğrencilerin mezuniyet sonrası veya öğrenim hayatları boyunca girişimcilik cesaretleri ve yenilikçi fikirlerini kaybetmeden bunları en uygun şartlar ve yeterli altyapı ile hayata geçirmelerini sağlayacaktır.

\section{Transfer ve İletişim Merkezi}

"Kariyer Geliştirme Merkezi"nin etkin olduğu süre boyunca açık ve sürekli bir iletişim ortamının oluşmasını sağlayacak bu birim öğrenciler, paydaşlar ve diğer birimler arasındaki bilgi açığı ve kopmaları önlemekten sorumludur. Tanıtım ve duyuruların yapılması, toplantıların ve etkinliklerin planlanması gibi kurumsal iletişim faaliyetlerini yürüten birim aynı zamanda bir halkla ilişkiler merkezi olarak da görev yapmakta sürekli olarak öğrenci, eğitimci ve paydaşlardan gelen geri bildirimleri değerlendirip, merkeze yönlendirmektedir. Transfer işlevi ise bu süreçte devreye girmekte ve birim merkezin "üniversite içi ve dışına" açılan kapısı işlevi görmektedir. Öyle ki, öğrencilerin, mezunların, paydaşların, eğitimcilerin ve medyanın arasında bir iletici konumunda olmak birimin önemini ortaya koymaktadır.

Birimin işlevlerini tümüyle yerine getirmesi diğer tüm birimlerin uyum içerisinde çalışmasını, görev dağımının uygun bir biçimde yapılması ve faaliyet planlarına uyulması açısından büyük bir önem arz etmektedir.

\section{Sosyal, Beşeri ve Psikoloji Sermaye Gelişim Birimi}

Bireyler ve dâhil oldukları toplumsal ağlar arasındaki bağlantıları, karşılıklılık normlarını ve güveni temsil eden sosyal sermaye kavramı (Putnam, 2001, 19) bireyin toplum içinde gelişimi ve toplumun bireylerin faaliyetleri aracılığıyla ilerlemesini ifade etmektedir. Buna göre birimin sosyal sermayeye yönelik faaliyetleri öğrencilerin mevcut veya potansiyel toplumsal ağlarla olan ilişkilerini geliştirmeyi amaçlamaktadır. Bu yolla girişimciliğe adım adan gençler ağlarının sağlayabileceği desteği tüm gücüyle arkasına alabilecektir

İş ve ekonomik değer oluşturabilecek; bilgi, deneyim, alışkanlık, kişisel ve toplumsal özellikler ve yaratıcılıktan oluşan bir bütünü (Goldin, 2004, 22; Işık ve Ünlü, 2013, 150) temsil eden beșeri sermaye olgusundan hareketle "Kariyer Geliştirme Merkezi" faaliyet alanlarına eklenen bu alt birim, özellikle öğrenci girişimlerinin ülke ekonomisine sağlayacağı katkıya yönelik olarak hizmet etmektedir. Öyle ki açılacak işletmenin beraberinde çalışanların taşıdıkları öznitelikler de girişimin başarısını birincil derecede etkileyen bir faktör olarak değerlendirilmektedir.

Öz-yeterlilik, iyimserlik, umut ve direnç unsurlarının bir araya gelmesinden oluşan, bireyin psikolojik yapısının olumlu bir düzlemde gidişat sürdürmesi için çaba sarf eden psikolojik sermaye (Luthans ve Youssef, 2004) olgusundan beslenen alt birim, öğrencilerin; girişim kurmak ve bu girişimin devamlılığı için gerek duyduğu öz güven 
ve yeterliliği kazanmada, mevcut durumda eldeki değerlerin farkında olunması, geleceğe yönelik olumlu beklentiler içinde olma ve karşılaşılan zorluklara karşı koyabilme becerilerine katkı sağlamaktadır.

\section{Üniversite Temsilciği}

Birim üniversite rektörü ve fakülte dekanlarının kendi birimlerinden görevlendirdiği öğretim üyelerinden ve üniversite öğrenci temsilcilerinden oluşmaktadır. Üniversite temsilciliği "Kariyer Geliştirme Merkezi" ile doğrudan haber ve bilgi paylaşımında olan denetleyici bir kurulu olarak görev yapmaktadır. Birimin varlığı bir taraftan hesap verilebilirlik ve sorumluluk ilkelerinin bir göstergesi olarak Kariyer Geliștirme Merkezinin faaliyetlerinin belirli aralıklarla kontrolünü sağlarken diğer taraftan Kariyer Geliştirme Merkezinin faaliyetlerini meşru bir çerçeve içerisinde tutan bir teminat niteliği taşımaktadır.

$\mathrm{Bu}$ birimin bir diğer özelliği ise üniversite öğrenci temsilcilerini yapısında barındırmasıdır, buna göre öğrenciler belirli sınırlar dâhilinde öğrenci Kariyer Geliştirme Merkezi'nin işleyişi ve faaliyetlerine ilişkin olarak kurula fikir ve önerilerine katılımcılık esaslı olarak sunabilmektedir.

Yukarıda vurgulanan katılımcılık hususu bireylerin hayatlarını etkileyebilecek kararları verme ve toplumsal yapılara dahil olma süreci olarak ifade edilebilmektedir. $\mathrm{Bu}$ süreç bir taraftan öğrencinin mezuniyet sonrası seçeceği iş alanı fark etmeksizin girişimcilik yetenekleri ve öz güvenin gelişmesi doğrultusunda önemli bir aracı olma potansiyeli anlamına gelirken diğer taraftan öğrencinin görüş ve kanaatlerini dile getirerek hem kendi yaşamını hem de toplumsal yaşamı iyileștirme firsatını ona sunmaktadır (Işılk, Ünlü Kurt ve Kurt, 2017: 79-81).

\section{Sektör Temsilciği}

Birim üniversite dışından öğrencilerin girişimde bulunması muhtemel alanlarda gönüllü olarak merkeze dâhil olan sektör temsilcilerini barındırmaktadır. Sektör temsilcileri bir taraftan geliştirilen fikirlerin sektör şartları bağlamında değerlendirirken, diğer taraftan öğrencilere staj imkanı ve deneyimlerini sunmaktadır.

Sektör temsilciliğinin barındıracağı zenginlik Kariyer Geliştirme Merkezi'nin başarısının belirleyici ana faktörlerden biri olacaktır. Öyle ki, farklı sektörlerden başarılı isimlerden deneyim kazanma imkânı öğrenciler için önemli bir teşvik olarak görülmektedir. Birimi atölyelerin işleyişinden ayıran nokta ise süreklilik hususudur, atölyelerde verilen eğitimlerin dışarıya taşınması ve öğrencilerin kazanımlarını sektör şartlarında değerlendirmesinin sağlanması bu birimin asli görevidir.

\section{Yönetim}

Birim Kariyer Geliştirme Merkezi'nin denetim ve idaresinin sağlanmasından sorumludur. Buna göre merkezin genel işleyişinin kontrolü, görevlendirmelerin yapılması ve yetkilendirmeler bu birim tarafından gerçekleştirilmektedir. Sorumlu öğretim üyesinin idaresini yürüttüğü birim, diğer birimlerden gelen periyodik rapor ve bilgilendirmelerle merkezin idaresini yürütmektedir.

Birim denetim görevinin beraberinde öğrencilerin "liderlik" yetkinliklerini arttırmak adına da görev yapmaktadır. Birim dâhilinde görevlendirilen öğrenciler dönüşümlü olarak yapılan atamalar yardımıyla farklı birimler dâhilinde; iletişim, planlama, 
kurumsallık, örgüt yönetimi ve işletme gibi farklı konularda yetkinlik kazanarak başarılı birer girişimci ve yönetici olma yolunda adım atarlar.

\section{Sonuç}

Değer ve fırsat yaratma yönlü girişimcilik çabaları olarak karşımıza çıkan öğrenci girișimciliği, inovatif veya uyarlanabilir eylemleri öğrencilerin sürece dahil olarak iş fırsatlarına çevirmesi yolunda adımlar atmasını sağlayan yeni bir süreç olarak uygulanmaktadır. Çalışma bu yeni tür girișimcilik bağlamında ülkemiz üniversitelerinde uygulanabilecek sistematik bir model önerisinde bulunmaktadır. “Kariyer Geliştirme Merkezi Modeli'nin bu çalışma kapsamında aktarılan şekliyle uygulama safhasında önemli eksiklikleri barındırsa da önerilen kavramsal model gelecekte atılacak adımlar için bir yol haritası çizilmesi ve konu hakkında farkındalığın arttırılması anlamında önemli görülmektedir.

Ülkemizde fikirlerin geliştirilmesi için üniversiteler dahilinde çeşitli kuluçka ve ArGe merkezleri bulunsa da bu merkezlerin öğrencileri teşvik edici ve/veya onları fikirlerini hayata geçirmeye yöneltecek faaliyetleri bulunmamakta bu merkezler yalnızca belirli alanlardan öğretim üyelerinin projelerindin hayata geçirilmesi için kullanılan platformlar olarak görev yapmaktadır. Ancak yukarıda da belirtildiği üzere gençlerin "işlenmemiş" de olsa fikirleri, tecrübeleri ve aldıkları duyumlar neticesinde zihnindeki belirli kalıplarla hareket eden "yetişkin"lerden farklı olarak gerçek anlamda ekonomik ve toplumsal etki yaratabilecek potansiyele sahiptir. Ülkemiz gençliğinin üniversitelerde aldığı girişimcilik eğitimi onlara bu değişimi yaratabilecek cesareti verememekte ve hatta bu konuda onların cesaretini kırmakta ve yeni mezunları gerekli eğitim ve altyapıyı kazanmaya teşvik edip kendi işletmelerini kurmaktansa sektörün zorlu şartlarına yeterli tecrübeyi elde edemeden itmektedir. "Kariyer Geliştirme Merkezi" bu süreçte devreye girmekte ve öğrencileri girişimciliğe teşvik etmeye veya en azından eğilim gösterdikleri sektörü tanıma firsatı sunmaya çabalamaktadır.

\section{Kaynakça}

Brockhaus, R. H., ve Horwitz P.S. (1986). “The Psychology of the Entrepreneur," in The Art and Science of Entrepreneurship. Eds. D. L. Sexton and R. W. Smilor. Cambridge, MA: Ballinger Publishing Company, 25-48.

Donckels, R. (1991). "Education and Entrepreneurship Experiences from Secondary and University Education in Belgium," Journal of Small Business and Entrepreneurship 9(1), 35-42.

Donnellon, A., Ollila, S. ve Middleton, K.W. (2014), “Constructing entrepreneurial identity in entrepreneurship education", The International Journal of Management Education, Vol. 12 No. 3, pp. 490-499.

Galloway, L., ve Brown W. (2002). "Entrepreneurship Education at University: A Driver in the Creation of High Growth Firms?," Education and Training $44(8 / 9), 398-405$.

Gilbert, B. A., Audretsch D. B. ve McDougall P. P. (2004). "The Emergence of Entrepreneurship policy," Small Business Economics 22(3/4), 313-323.

Goldin C. (2014). Human Capital Harvard University and National Bureau of Economic Research. 
Gupta, A. ve Gupta, V. K. (2017) "Just a Lemonade Stand: An Introduction to Student Entrepreneurship," New England Journal of Entrepreneurship: Vol. 20 : No. 1 , Article 3.

Howorth, C., Smith, S.M. ve Parkinson, C. (2012), "Social learning and social entrepreneurship education", Academy of Management Learning and Education, Vol. 11 No. 9, pp. 371-389.

Kantor, J. (1988). “Can Entrepreneurship Be Taught?-A Canadian Experiment," Journal of Small Business and Entrepreneurship 5(4), 12-19.

Işıı, M. ve Ünlü, S. (2013). "Sosyal Sermaye Geliştirme Sürecinde Akademik Girișimciliğin Rolü: 3+1 Eğitim Modeli Örneği ." I. Uluslararası Girişimcilik ve Kariyer Sempozyumu, 1-3 Kasım, Muğla, 143-152.

Işık, M. ve Ünlü, S. (2014). “Sosyalleşme ve Toplumsal Değişim Aracı Olarak Gençlik Sosyal Girişimciliği: Zumbara Örneği.” Gençlik Araştırmaları Dergisi, 2(3), 366-383.

Işık, M., Ünlü Kurt, S. ve Kurt, M. C., (2017), “Değişen Bir Katılım Mekanizması Olarak Gençliğin Toplumsal Katılımı." Gençlik Araştırmaları Dergisi, 5(13), 77-86.

Johannisson, B. (1991). "University Training for Entrepreneurship: Swedish Approaches," Entrepreneurship and Regional Development 3(1), 67-82.

Luthans F., ve Youssef, C.M. (2004). Human, social, and now positive psychological capital management: Investing in people for competitive advantage, Organizational Dynamics, 33(2), 143-160.

Ndirangu, M., ve Bosire, J. (2004). “Student entrepreneurship on campus: A survival response or a career rehearsal? The case of Egerton University student entrepreneurs." EASSRR, 20(1): 51-66.

Putnam R. D. (2001). Bowling Alone: The Collapse and Revival of American Community. Simon and Schuster.

Ridder, A., ve Sijde, P. (2006). "Launching students into enterprises: Experiences with technology as the launching platform." International Journal of Knowledge Management Studies, 1(1/2): 121-132.

Rigg, C. ve O’Dwyer, B. (2012), “Becoming an entrepreneur: researching the role of mentors in identity construction", Education + Training, Vol. 54 No. 4, pp. 319329.

Robinson, S., Neergaard, H., Tanggaard, L. ve Krueger, N. (2016), "New horizons in entrepreneurship: from teacher-led to student-centered learning", Education + Training, Vol. 58 Nos 7/8, pp.661-683.

Ronstadt, R. (1985). “The Educated Entrepreneurs: A New Era of Entrepreneurial Education Is Beginning," American Journal of Small Business 10, 7-23.

Van Stel, A., Carree M., ve Thurik R. (2005). “The Effect of Entrepreneurial Activity on National Economic Growth," Small Business Economics 24(3), 311-321.

Vesper, K. H., ve Gartner, W. B. (2001). Compendium of entrepreneur programs. University of Southern California, Lloyd Greif Center for Entrepreneurial Studies, Los Angeles. 
